\title{
Peroral Endoscopic Myotomy for Esophageal Achalasia in Portugal: Outcomes of the First Prospective Series
}

\author{
Rui Mendo ${ }^{a}$ Pedro Barreiro ${ }^{a, b}$ José Rodrigues ${ }^{a}$ Catarina Félix ${ }^{a}$ \\ Catarina O'Neill $^{\mathrm{a}}$ lala Carina ${ }^{\mathrm{a}}$ Joyce Chivia $^{\mathrm{a}}$ Cristina Chagas $^{\mathrm{a}}$ \\ a Department of Gastroenterology, Centro Hospitalar Lisboa Ocidental, Hospital de Egas Moniz, Lisbon, Portugal;

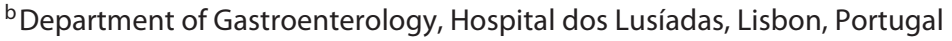

\section{Keywords}

Achalasia $\cdot$ Peroral endoscopic myotomy

\section{Abstract}

Background: Peroral endoscopic myotomy (POEM) is an innovative achalasia treatment procedure that involves myotomy of the lower esophageal sphincter through a submucosal tunneling approach, combining the efficacy of surgical myotomy with the benefit of being a less invasive treatment. At this time, no data are available of POEM in Portugal. This study aimed to examine the safety and short-term outcomes of POEM in a Portuguese center. Methods: Fifty POEM were performed on 49 consecutive patients at our institution between January 2017 and January 2020. A prospective study of a consecutive series of patients was conducted, including procedure time, myotomy location and length, adverse events and clinical success. An Eckardt score of $\leq 3$ after POEM was deemed as a successful outcome. Gastroesophageal reflux disease (GERD) was evaluated based on symptoms and on upper endoscopy, which was performed at 3-6 months postoperatively to check for reflux esophagitis. $\boldsymbol{R e}$ sults: POEM was successfully completed in all cases: $70 \%$ $(n=35)$ were naïve and $30 \%(n=15)$ had previous treat-

karger@karger.com www.karger.com/pjg

Karger

bOPEN ACCESS
(C) 2020 Sociedade Portuguesa de Gastrenterologia Published by S. Karger AG, Basel

This is an Open Access article licensed under the Creative Commons Attribution-NonCommercial-4.0 International License (CC BY-NC) (http://www.karger.com/Services/OpenAccessLicense), applicable to the online version of the article only. Usage and distribution for commercial purposes requires written permission. ments. The mean procedure time was $73.4 \pm 22.6 \mathrm{~min}$ (range 45-125 min). There were no major adverse events. Minor adverse events were rare (8\%), and there was no perioperative mortality. The Eckardt score significantly decreased from 6.9 \pm 2.4 preoperatively to $0.5 \pm 1.0$ postoperatively $(p<0.05)$. Overall clinical success was documented in 98,98 and $95.2 \%$ at 1,3 and 6 months, respectively. These short-term outcomes after POEM were independent of previous treatments. Symptomatic GERD was seen in $22.4 \%$ of patients. Conclusions: Our results confirm the safety and excellent short-term efficacy of POEM in a Portuguese center. This supports POEM as one of the first-line achalasia therapies in Portugal when performed by experienced operators.

(c) 2020 Sociedade Portuguesa de Gastrenterologia Published by S. Karger AG, Basel

\section{Miotomia endoscópica peroral na acalásia em Portugal: Resultados da primeira série prospectiva}

Palavras Chave

Acalásia $\cdot$ Miotomia endoscópica peroral 


\section{Resumo}

Introdução: A miotomia endoscópica peroral (POEM) é um procedimento terapêutico inovador da acalásia que envolve a miotomia do esfíncter esofágico inferior através de uma abordagem por tunelização da submucosa, combinando a eficácia da miotomia cirúrgica com o benefício de ser um tratamento menos invasivo. Atualmente não existem dados disponíveis relativamente à aplicação do POEM em Portugal. Este estudo teve como objetivos examinar a segurança e os resultados a curto-prazo do POEM num centro português. Métodos: Cinquenta POEM foram realizados em 49 doentes consecutivos na nossa instituição entre Janeiro 2017 e Janeiro 2020. Foi realizado um estudo prospetivo numa série consecutiva de doentes, incluindo tempo do procedimento, localização e extensão da miotomia, eventos adversos e sucesso clínico. O sucesso clínico foi definido como um score de Eckardt $\leq 3$ após o procedimento. A doença do refluxo gastroesofágico (DRGE) foi avaliada com base na sintomatologia e na realização de endoscopia alta entre os 3 e 6 meses pós-procedimento. Resultados: O POEM foi realizado com sucesso em todos os casos: $70 \%(n=35)$ eram naïves e $30 \%$ ( $n=15)$ já tinham realizado algum tratamento previamente. $\mathrm{O}$ tempo médio do procedimento foi de $73.4 \pm 22.6 \mathrm{~min}$ (intervalo 45-125 min). Não se verificou nenhum evento adverso major. Os eventos adversos minor foram raros (8\%) e não se verificou mortalidade perioperatória. O score de Eckardt diminuiu significativamente de $6.9 \pm 2.4$ pré-procedimento para $0.5 \pm 1.0$ pósprocedimento ( $p<0.05$ ). Verificou-se sucesso clínico global em 98, 98 e 95.2\% ao 1, 3 e 6 mês pós-procedimento, respetivamente. Estes resultados após o procedimento foram independentes de tratamentos prévios. Sintomatologia sugestiva de DRGE foi observada em $22.4 \%$ dos doentes pós-procedimento. Conclusões: Os resultados confirmam a segurança e a excelente eficácia no curtoprazo do POEM num centro português, suportando o POEM como uma das terapêuticas de primeira linha para a acalásia em Portugal quando realizada por operadores experientes. ๑ 2020 Sociedade Portuguesa de Gastrenterologia Publicado por S. Karger AG, Basel

Achalasia is an esophageal motility disorder that results from progressive degeneration of ganglion cells in the myenteric plexus of the esophagus, resulting in impaired lower esophageal sphincter (LES) relaxation accompanied by a loss of peristalsis of the esophageal body [1-3]. As a result, patients have various related symptoms including dysphagia, regurgitation and chest pain $[2,4]$. It is an un-

Peroral Endoscopic Myotomy for Esophageal Achalasia in Portugal common disorder, with an estimated annual incidence of approximately 1.6 cases per 100,000 individuals and a prevalence of 10.9 cases per 100,000 individuals [5].

Unfortunately, there are no treatments available that can reverse the degeneration of the myenteric plexus and restore lost esophageal neuron function. Therefore, treatment options aim to relieve symptoms by decreasing the resting pressure in the LES to a level at which the sphincter no longer restrains the passage of ingested material. Classically, this can be accomplished by pharmacological reduction in LES pressure (botulinum toxin injection) or by mechanical disruption of the muscular layer of the LES (endoscopic balloon dilation and Heller myotomy surgery) [1]. However, the effectiveness of botulinum toxin injection is temporary, and patients often need to repeat this treatment option [1]. Endoscopic balloon dilation usually involves a "graded dilation" strategy that allows progression to larger balloons if needed, potentially requiring multiple treatment procedures $[1,6,7]$. The longterm therapeutic success rate, defined as a reduction of the Eckardt score to less than or equal to 3 and the absence of the need for retreatment, is $50-85 \%$ [6]. Surgical myotomy has long been considered the most definitive treatment for achalasia, although a recent meta-analysis reported mean 5- and 10-year remission rates of 76.1 and $79.6 \%$, respectively [8].

Recent advances in endoscopic techniques and devices have led to the development of a novel endoscopic treatment of achalasia, namely peroral endoscopic myotomy (POEM), which allows myotomy of the distal esophagus and the LES through an endoscopic submucosal tunneling approach [9]. Inoue et al. [9] developed POEM as an alternative therapy for achalasia and reported the first case in 2009. POEM represents an innovative endoscopic procedure that has been established as an effective treatment option for achalasia, being associated with a very low rate of severe adverse events when performed by experienced operators [1,9-12]. Despite the excellent results published worldwide, data are scarce regarding the use of this technique in Portugal, limited to case reports [13-16]. Therefore, we aimed to evaluate procedure data as well as the short-term outcomes of the first 50 POEM procedures in a Portuguese center.

\section{Methods}

Patients

To assess POEM safety and effectiveness, a prospective study of a consecutive series of patients was conducted, after ethics committee approval. Fifty POEM procedures were performed in 49 


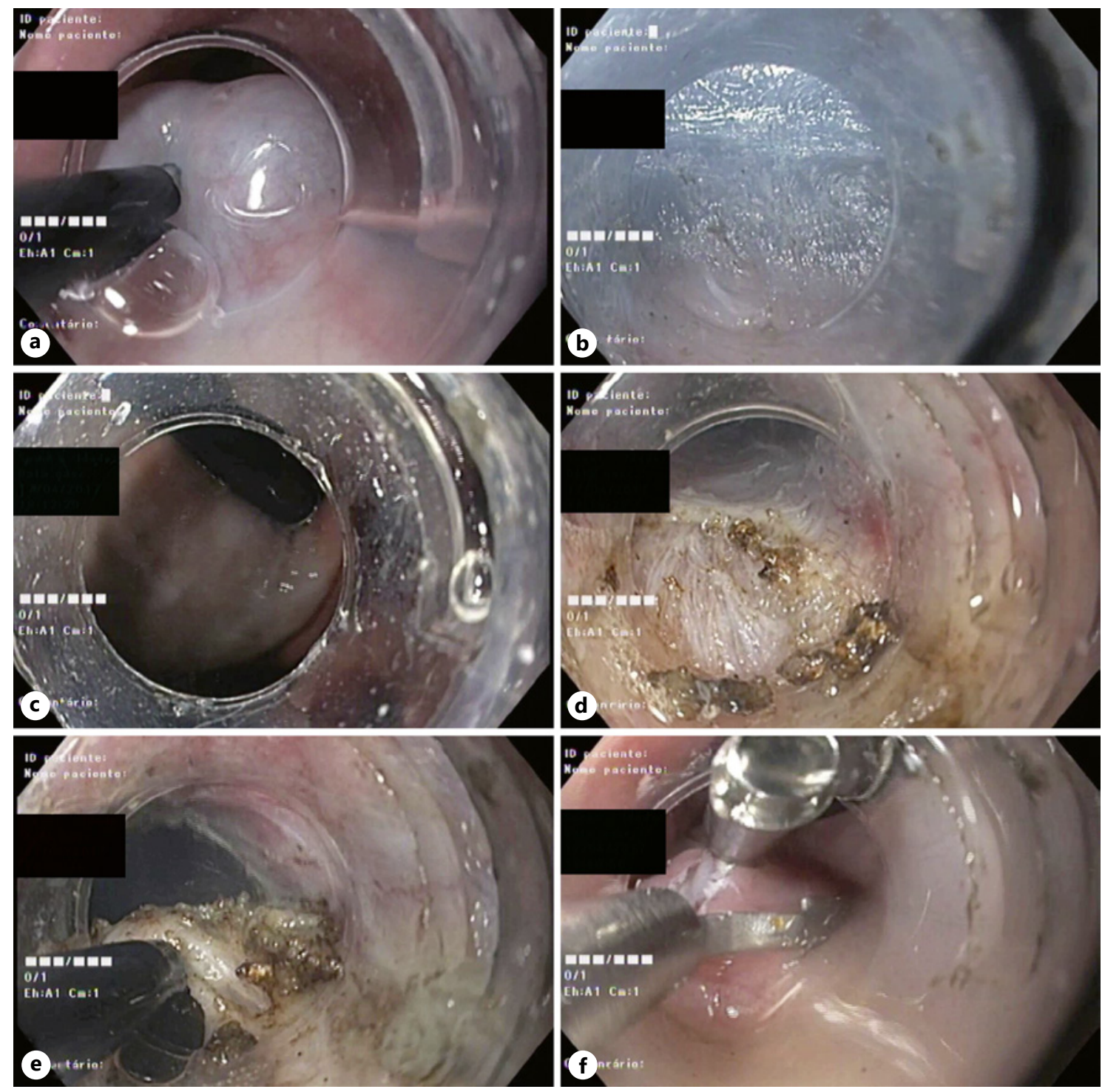

Fig. 1. Main steps of the POEM procedure. a Mucosal entry after submucosal injection for accessing the submucosa. b Submucosal tunneling near muscularis propria. c Bluish discoloration seen in the cardia on gastric retroflexion confirming adequate tunnel length. d Selective myotomy of the circular fibers of the esophagus. e Fullthickness myotomy of the cardia and gastric side. $\mathbf{f}$ Mucosal entry closure using hemostatic clips.

consecutive patients with a confirmed diagnosis of achalasia in a Portuguese tertiary referral center, from January 2017 through January 2020. Patients diagnosed with achalasia were included. The inclusion criteria for POEM were a confirmed diagnosis of achalasia by high-resolution manometry, a pretreatment Eckardt score $>3$ and patient verbal and written consent after detailed explanation of all treatment options [1]. Patients were excluded if they had portal hypertension, severe chronic obstructive pulmonary disease, thrombocytopenia $(<50,000 / \mu \mathrm{L})$ or coagulopathy (INR $>1.5$ ), patients who could not stop antithrombotic therapy or were unable to undergo general anesthesia and those who declined treatment with POEM. All patients signed a consent form to enter in the study in addition to the consent for the procedure.

\section{Clinical Assessment}

Clinical symptoms were assessed using the Eckardt score. Preoperative tests, including endoscopy, high-resolution esophageal manometry and barium swallow were performed in all patients.

\section{POEM Equipment}

A high-resolution endoscope (GIF-HQ190, Olympus ${ }^{\circledR}$ ) with an outer diameter of $9.9 \mathrm{~mm}$ was used with a transparent distal cap attachment (ST Hood, Fujifilm ${ }^{\circledR}$ ). We used the Triangle Knife (Olympus ${ }^{\circledR}$ ) as a single knife for all steps of the procedure. The coagulating forceps (Coagrasper, Olympus ${ }^{\circledR}$ ) was used to coagulate larger vessels prior to dissection and for hemostasis. All procedures were performed with carbon dioxide gas $\left(\mathrm{CO}_{2}\right)$ insuffla- 
tion. Finally, hemostatic clips were used for the closure of the mucosal entry site.

\section{POEM Procedure}

At the time of the POEM procedure, all patients were kept in the supine position, with the endoscopist standing to the left of the patient. The procedures were performed in the operating room under general anesthesia with endotracheal intubation. The procedural time was defined as the time needed from the insertion of the scope until its removal.

All procedures were performed by the same endoscopist (P.B.), with expertise in endoscopic submucosal dissection, after animal training and assisting experts in live cases. The procedures were done according to the technique of Inoue et al., consisting in mainly 4 steps [17]: (1) mucosal incision and tunnel entry; (2) submucosal tunneling; (3) endoscopic myotomy; (4) closure of the mucosal entry. After the creation of a submucosal lift by injecting a colloid with indigo carmin solution in the submucosa (Fig. 1a), a 15-20 mm longitudinal mucosal incision was made to access the submucosal space. The location of the initial mucosal incision was decided such that there were, by the end of the procedure, $2-3 \mathrm{~cm}$ of submucosal tunnel segment remaining between the mucosal incision and the proximal side of the myotomy. Depending on the desired length of myotomy and indication for POEM, the mucosal incision was done about $10-12 \mathrm{~cm}$ above the gastroesophageal junction except in achalasia type III where we performed a more extensive myotomy. In the cases of anterior myotomy, a submucosal tunnel was created in the 1- to 2-o'clock position and in posterior myotomy at the 5- to 6-o'clock position. Despite some theoretical aspects, comparative studies between both approaches do not show different results either in terms of efficacy, complications or reflux rate [7]. So, by decision and comfort of the endoscopist, we chose the anterior approach as the preferred approach, and used a posterior approach if a long myotomy was needed (e.g., type III achalasia - anecdotal cases of tracheoesophageal fistulas after anterior approach), in the case of previous Heller myotomy or POEM with anterior approach (to avoid submucosal fibrosis) and in the cases of sigmoid esophagus with a very large lumen (technically difficult in performing an anterior approach by angulation of the device).

After the mucosal incision, the endoscope with a distal cap was then advanced into the submucosal layer and a submucosal tunnel was created by careful submucosal dissection near the muscularis propria (Fig. 1b), and this was extended across the LES and into the gastric side for approximately $2-3 \mathrm{~cm}$. This was confirmed by the typical landmarks at the gastroesophageal junction and cardia (submucosal space narrowing and then widening, the presence of penetrating vessels in the gastric side and by the bluish discoloration seen in the cardia on retroflexion (Fig. 1c) [17-19]. Afterwards, a proximal-to-distal partial full-thickness myotomy was performed (selective myotomy of circular fibers in the esophagus and full-thickness myotomy in the cardia and gastric side) (Fig. 1de). After completing the myotomy, antibiotic irrigation of the submucosal tunnel was performed with gentamycin. The scope was then withdrawn, and the mucosal incision was closed using hemostatic clips (Fig. 1f).

POEM In-Hospital Schedule and Surveillance Schedule

Patients were told to use a liquid diet on the 2 days before the procedure. They were admitted on the day of the procedure and were placed on nil per os. On the day after POEM, a barium esophagogram was performed to exclude esophageal leakage, after which a liquid diet was allowed. On the 2 nd day after the procedure patients were typically discharged on a soft diet and were told to gradually restart a regular diet on the first 5-7 days after the procedure.

A prophylactic antibiotic with ceftriaxone was given peri- and postprocedurally during the in-hospital stay (2 days). On discharge, patients were prescribed ciprofloxacin and metronidazole for 5 additional days. Additionally, a proton pump inhibitor (PPI) was prescribed for 6-8 weeks postoperatively only after which they were discontinued until postoperative reevaluation. The follow-up visits after the POEM procedure were at 1 week, 1, 3 and 6 months postoperatively and every 6 months afterwards. Achalasia-related symptoms were assessed using the Eckardt score and compared with preoperative data. Gastroesophageal reflux disease (GERD) was assessed based on symptoms and upper endoscopy, which was performed at 3-6 months postoperatively to check for erosive esophagitis.

\section{Definitions}

Technical success was defined as complete esophageal-gastric myotomy. Clinical success was defined as an Eckardt score $\leq 3$ after POEM. Adverse events were defined as those requiring a specific intervention such as insufflation-related events requiring drainage, bleeding, mucosal injury and those leading to prolonged hospitalization. Major adverse events were defined as hemodynamic instability, intensive care unit stay, re-admission, invasive postoperative procedure, blood transfusion or prolonged $(>5$ days) hospitalization [8]. Intraprocedural severe bleeding was defined as a bleeding occurring during the procedure with hemodynamic instability, need of blood transfusion or ineffective endoscopic hemostasis. Intraprocedural minor bleeding was defined as a bleeding occurring during the procedure that takes more than 5 min until endoscopic hemostatic control and without severe bleeding features.

\section{Statistical Analysis}

All statistical analyses were conducted using the Statistical Package for the Social Sciences software version 22 (IBM). The data were analyzed by Student's $t$ test. $p$ values $<0.05$ were considered as statistically significant.

\section{Results}

\section{Patient Characteristics}

Fifty POEM procedures were done on 49 adult patients with achalasia, including 22 men and 27 women (Table 1). The average age was $53.9 \pm 16.6$ (range 17-79) years. According to the Chicago classification system, esophageal manometry findings were classified as type I (14 patients, $28 \%$ ), type II (30 patients, $62 \%$ ) and type III (5 patients, 10\%). Twelve patients (24\%) had undergone previous balloon dilation, 2 patients (4\%) had undergone prior surgical myotomy and 1 patient (2\%) had undergone prior POEM. 
Table 1. Patient characteristics

\begin{tabular}{ll}
\hline Patients, $n$ & 49 \\
POEM, $n$ & 50 \\
Mean age \pm SD (range), years & $53.9 \pm 16.6(17-79)$ \\
Gender (male:female) & $22: 27$ \\
Chicago classification, $n(\%)$ & \\
$\quad$ Type I & $14(28)$ \\
$\quad$ Type II & $31(62)$ \\
Type III & $5(10)$ \\
Naïve to treatment, $n(\%)$ & $35(70)$ \\
Previous treatment, $n(\%)$ & $15(30)$ \\
$\quad$ Pneumatic dilation & $12(24)$ \\
Heller's myotomy (laparoscopic) & $2(4)$ \\
POEM & $1(2)$ \\
\hline
\end{tabular}

Table 2. Procedure-related parameters

$\begin{array}{lc}\text { Mean procedure time } \pm \text { SD (range), min } & 70 \pm 22(45-125) \\ \text { Mean myotomy length } \pm \text { SD (range), cm } & 11 \pm 3(6-20) \\ \text { Esophageal side } & 7.94 \pm 2.8(5-17) \\ \text { Gastric side } & 3.2 \pm 0.8(2-5) \\ \text { Myotomy location, } n(\%) & \\ \text { Anterior } & 40(80) \\ \text { Posterior } & 10(20) \\ \text { Adverse events, } n(\%) & 4(8) \\ \text { Intraprocedural minor bleeding } & 2(4) \\ \text { Capnoperitoneum requiring drainage } & 1(2) \\ \text { Dorsalgia (muscle contracture) } & 1(2)\end{array}$

Table 3. Comparison of the therapeutic effect in relation to the presence or absence of previous treatment history

\begin{tabular}{|c|c|c|c|}
\hline & $\begin{array}{l}\text { Naïve } \\
(n=35)\end{array}$ & $\begin{array}{l}\text { Previous procedure } \\
(n=15)\end{array}$ & $p$ value \\
\hline Gender (male/female) & $17 / 18$ & $4 / 11$ & 0.144 \\
\hline Age, years & $52.9 \pm 17.2$ & $56.5 \pm 15.6$ & 0.476 \\
\hline Chicago classification & & & 0.068 \\
\hline Type I & 8 & 6 & \\
\hline Type II & 22 & 9 & \\
\hline Type III & 5 & 0 & \\
\hline \multicolumn{4}{|l|}{ Site of myotomy, n (\%) } \\
\hline Anterior & $30(85.7 \%)$ & $10(66.7 \%)$ & \\
\hline Posterior & $5(14.3 \%)$ & $5(33.3 \%)$ & \\
\hline Mean length of myotomy $\pm \mathrm{SD}, \mathrm{cm}$ & $11.4 \pm 3.3$ & $10.5 \pm 2.1$ & 0.254 \\
\hline Esophageal myotomy & $8.22 \pm 3.1$ & $7.3 \pm 1.6$ & 0.159 \\
\hline Gastric myotomy & $3.1 \pm 0.7$ & $3.2 \pm 0.9$ & 0.822 \\
\hline \multicolumn{4}{|l|}{ Mean Eckardt score \pm SD } \\
\hline Preoperative & $6.9 \pm 2.3$ & $6.7 \pm 2.5$ & 0.813 \\
\hline 1 month postoperative & $0.3 \pm 0.7$ & $0.9 \pm 1.3$ & 0.124 \\
\hline 3 months postoperative & $0.5 \pm 0.9$ & $0.5 \pm 0.9$ & 0.903 \\
\hline 6 months postoperative & $0.8 \pm 1.3$ & $0.9 \pm 1.1$ & 0.920 \\
\hline \multicolumn{4}{|l|}{ Clinical success, n/total (\%) } \\
\hline 1 month after POEM & $35 / 35(100)$ & $14 / 15(93.3)$ & \\
\hline 3 months after POEM & $34 / 34(100)$ & $14 / 15(93.3)$ & \\
\hline 6 months after POEM & $27 / 28(96.4)$ & $13 / 14(92.9)$ & \\
\hline Mean procedure time $\pm \mathrm{SD}, \min$ & $74.2 \pm 22.7$ & $73.1 \pm 20.3$ & 0.891 \\
\hline Adverse events, n (\%) & $3(8.6)$ & $1(6.6)$ & \\
\hline Mean postoperative stay $\pm \mathrm{SD}$, days & $2.1 \pm 0.2$ & $2.1 \pm 0.5$ & 0.591 \\
\hline
\end{tabular}

$\mathrm{SD}$, standard deviation.

\section{Results of POEM}

POEM was technically successful in all cases. The average total length of endoscopic myotomy was $11.1 \pm$ $3.0 \mathrm{~cm}$ (range $6-20 \mathrm{~cm}$ ), with an average length of the gastric myotomy of $3.2 \pm 0.8 \mathrm{~cm}$ (range $2-5 \mathrm{~cm}$ ) (Table
2). In most cases, an anterior myotomy was performed (40 patients, $80 \%$ ). The mean procedure time was 73.4 $\pm 22.6 \mathrm{~min}$ (range $45-125 \mathrm{~min}$ ). All the adverse events related to POEM were minor $(n=4,8 \%)$ and were observed in 3 patients: 2 cases of intraprocedural minor 
Table 4. Evaluation of gastroesophageal reflux disease (GERD) after the procedure

\begin{tabular}{lc}
\hline Symptomatic GERD, $n /$ total (\%) & $11 / 49(22.4)$ \\
Erosive esophagitis, $n /$ patients with follow-up & $14 / 43(32.6)$ \\
endoscopy (\%) & \\
LA classification & $12(27.9)$ \\
Grade A & $0(0)$ \\
Grade B & $2(4.6)$ \\
Grade C & $0(0)$ \\
Grade D & \\
\hline
\end{tabular}

LA, Los Angeles classification.
After a mean follow-up time of $13 \pm 9$ months, the rates of GERD and PPI use were $42 \%(n=21)$ and $40.8 \%(n=$ 20 ), respectively. Symptomatic GERD was seen in $22 \%$ of patients $(n=11)$, and $63.6 \%$ of those patients $(n=7)$ had no evidence of reflux esophagitis. Of the 43 patients with follow-up endoscopy, reflux esophagitis was seen in $32.5 \%(n=14)$ and $85.7 \%$ were classified as grade A reflux esophagitis according to the Los Angeles Classification (12 grade A; 2 grade $\mathrm{C}$; Table 4). Of those with reflux esophagitis, $71.4 \%(n=10)$ had no symptoms suggestive of GERD. Symptomatic GERD significantly improved in $81.8 \%$ of patients $(n=9)$ with oral PPI administration. None of the patients required antireflux surgery during follow-up.

\section{Discussion}

POEM is a novel high-risk and complex endoscopic procedure that requires advanced skills in gastrointestinal endoscopy. Accordingly, it is advisable to have experience in endoscopic submucosal dissection before embarking in performing POEM [20]. POEM is considered as a valid primary treatment for type I and II achalasia (as an alternative to endoscopic balloon dilation and surgical myotomy) and the decision between these treatment options should depend on local expertise and patient preference [1]. For type III achalasia, POEM has been proposed as the preferred treatment since it allows for a longer myotomy that is generally not possible with a surgical approach, allowing for a more effective symptomatic control caused by the esophageal spasm $[1,5]$.

In a retrospective study comparing POEM with laparoscopic surgical myotomy, POEM was associated with shorter procedural time and mean hospitalization as well as lower blood loss and post-procedure pain with lower analgesic requirements [11]. Another recent study comparing POEM with surgical myotomy demonstrated similar efficacy in relieving dysphagia (83 vs. $82 \%$, respectively) but a lower adverse event rate associated with POEM (2.7 vs. 7.3\%, respectively) [4]. As a result, POEM is currently considered a safe and effective treatment option for the management of achalasia due to the excellent overall efficacy when compared to laparoscopic surgical myotomy $[1,4,11]$.

In our cohort, the 1-month, 3-month and 6-month overall success rate was $98,97.9$ and $95.2 \%$, respectively. Only 1 patient had to undergo another POEM procedure due to absence of clinical response. Shiwaku et al. [21] had previously reported excellent short-term outcomes after 
POEM regardless of previous treatment. In order to determine the effect of the previous therapeutic history on POEM outcomes in our first case series, subgroup analysis was performed showing that improvements in Eckardt scores were independent of previous treatments (Table $3)$. Furthermore, there were no statistically significant differences in the length of myotomy and procedure time. The posterior myotomy rate was higher in patients with a prior treatment history (Table 3). Indeed, this was expected as posterior myotomy was performed during rescue POEM on the opposite side of previous surgical myotomy to avoid the fibrotic area $[22,23]$. Thus, this subgroup analysis revealed POEM as a safe and effective approach for achalasia regardless of previous treatment.

Overall, POEM appears to be a safe procedure, since it is associated with a low risk of adverse events and most of these can be managed conservatively or with endoscopic interventions [1, 10]. The rate of significant adverse events associated with POEM ranges from 2 to $4 \%[1,17]$. A recent study reported a $3.3 \%$ major adverse event rate associated with POEM, defined as hemodynamic instability, intensive care unit stay, readmission, invasive postoperative procedure, blood transfusion or prolonged $(>5$ days) hospitalization [10]. Accordingly, there were no major adverse events in our series. All the adverse events were minor and were managed either endoscopically or conservatively (Table 2). The percentage of patients who had minor adverse events were similar in naïve and previously treated patients, although definitions of minor adverse events vary in the literature (Table 3 ). Our cohort was not powered to assess differences in adverse events due to the absence of major adverse events coupled with a low rate of minor adverse events.

GERD has been the major drawback with POEM, especially because no antireflux mechanism is added during the procedure. In this study, symptomatic GERD was seen in $22.4 \%$ of patients, in line with recent reports [ 1,4 , $18,21]$. However, the rate of PPI use was higher (40.8\%). This is likely due to the number of patients with confirmed erosive esophagitis on upper endoscopy without symptomatic GERD. Despite this, erosive esophagitis and symptoms were easily controlled with PPI.

Our study confirms that POEM is an effective and safe procedure for achalasia with good short-term clinical outcomes. However, in order to guarantee safety and efficacy, we emphasize that it should be performed by experienced endoscopists after proper training in centers with a medium-to-high volume of cases. Regarding the application of the POEM procedure in esophageal motility disorders, and despite excellent results in the world- wide literature, no data have been published in Portugal until now. Since we are a referral center for POEM procedures in Portugal, we believe this prospective evaluation is essential to constantly audit our own performance and improve the technique, focusing on maintaining procedure safety and efficacy. To the best of our knowledge, this is the first case series of POEM in this country.

Regarding limitations, we highlight the fact that it was a single-center study performed by only one endoscopist, as well as the absence of long-term outcome evaluation.

In conclusion, our results confirm the excellent shortterm efficacy, as well as its safety, supporting POEM as one of the first-line achalasia therapies, irrespective of previous treatments performed. Further studies on longterm outcomes of POEM are eagerly awaited.

\section{Statement of Ethics}

All patients signed a consent form to enter the study (in addition to the consent for the procedure). The study was approved by the Ethics Committee of the Centro Hospitalar Lisboa Ocidental, EPE, in 2015.

\section{Conflict of Interest Statement}

The authors have no conflicts of interest to declare.

\section{Funding Sources}

The authors have no funding sources to declare.

\section{Author Contributions}

R.M., C.F., C.O., J.C., I.C. contributed to the acquisition, analysis and interpretation of data and drafting of the manuscript. P.B. and J.R. contributed to the conception and design of the work, drafting and critical revision of the manuscript for important intellectual content. C.C. contributed to the conception of this study, design and final approval of this version to be published.

References

1 Khashab MA, Vela MF, Thosani N, Agrawal D, Buxbaum JL, Abbas Fehmi SM, et al. ASGE guideline on the management of achalasia. Gastrointest Endosc. 2020 Feb;91(2):213227.e6.

2 Richter JE. Oesophageal motility disorders. Lancet. 2001 Sep;358(9284):823-8.

3 Kahrilas PJ, Bredenoord AJ, Carlson DA, Pandolfino JE. Advances in Management of Esophageal Motility Disorders. Clin Gastroenterol Hepatol. 2018 Nov;16(11):1692-700. 
4 Werner YB, Hakanson B, Martinek J, Repici A, von Rahden BH, Bredenoord AJ, et al. Endoscopic or Surgical Myotomy in Patients with Idiopathic Achalasia. N Engl J Med. 2019 Dec;381(23):2219-29.

5 Kahrilas PJ, Katzka D, Richter JE. Clinical practice update: the use of per-oral endoscopic myotomy in achalasia: expert review and best practice advice from the AGA Institute. Gastroenterology. 2017 Nov;153(5):1205-11.

6 Ponds FA, Fockens P, Lei A, Neuhaus H, Beyna T, Kandler J, et al. Effect of Peroral Endoscopic Myotomy vs Pneumatic Dilation on Symptom Severity and Treatment Outcomes Among Treatment-Naive Patients With Achalasia: A Randomized Clinical Trial. JAMA. 2019 Jul;322(2):134-44.

7 Mohan BP, Ofosu A, Chandan S, Ramai D, Khan SR, Ponnada S, et al. Anterior versus posterior approach in peroral endoscopic myotomy (POEM): a systematic review and meta-analysis. Endoscopy. 2020 Apr;52(4):2518.

8 Weber CE, Davis CS, Kramer HJ, Gibbs JT, Robles L, Fisichella PM. Medium and longterm outcomes after pneumatic dilation or laparoscopic Heller myotomy for achalasia: a meta-analysis. Surg Laparosc Endosc Percutan Tech. 2012 Aug;22(4):289-96.

9 Inoue $\mathrm{H}$, Minami $\mathrm{H}$, Kobayashi $\mathrm{Y}$, Sato $\mathrm{Y}$, Kaga M, Suzuki M, et al. Peroral endoscopic myotomy (POEM) for esophageal achalasia. Endoscopy. 2010 Apr;42(4):265-71.
10 Zhang XC, Li QL, Xu MD, Chen SY, Zhong YS, Zhang YQ, et al. Major perioperative adverse events of peroral endoscopic myotomy: a systematic 5-year analysis. Endoscopy. 2016 Nov;48(11):967-78.

11 Bhayani NH, Kurian AA, Dunst CM, Sharata AM, Rieder E, Swanstrom LL. A comparative study on comprehensive, objective outcomes of laparoscopic Heller myotomy with per-oral endoscopic myotomy (POEM) for achalasia. Ann Surg. 2014 Jun;259(6):1098-103.

12 Ngamruengphong $\mathrm{S}$, Inoue $\mathrm{H}$, Ujiki $\mathrm{MB}, \mathrm{Pa}$ tel LY, Bapaye A, Desai PN, et al. Efficacy and Safety of Peroral Endoscopic Myotomy for Treatment of Achalasia After Failed Heller Myotomy. Clin Gastroenterol Hepatol. 2017 Oct;15(10):1531-1537.e3.

13 Rio-Tinto R, Bispo M, Fidalgo P, Devière J. Peroral Endoscopic Myotomy for Achalasia Combined with Submucosal Marsupialization of an Epiphrenic Diverticulum. GE Port J Gastroenterol. 2020 Jan;27(1):50-2.

14 Rodrigues JP, Barreiro P, Carina I, Carvalho L, Figueiredo P, Chagas C. Peroral endoscopic myotomy with water pump-assisted submucosal tunnel creation. GE Port J Gastroenterol. 2018 Nov;25(6):331-2.

15 Baldaque-Silva F, Marques M, Ramalho R, Vilas-Boas F, Afonso M, Macedo G. Case description of cap retention in the submucosal tunnel during peroral endoscopic myotomy. Am J Gastroenterol. 2012 Oct;107(10):1586.

16 Baldaque-Silva F, Marques M, Vilas-Boas F, Maia JD, Sá F, Macedo G. New transillumination auxiliary technique for peroral endoscopic myotomy. Gastrointest Endosc. 2014 Apr;79(4):544-5.
17 Mittal C, Wagh MS. Technical Advances in Per-Oral Endoscopic Myotomy (POEM). Am J Gastroenterol. 2017 Nov;112(11):1627-31.

18 Inoue $\mathrm{H}$, Shiwaku $\mathrm{H}$, Iwakiri K, Onimaru M, Kobayashi Y, Minami H, et al. Clinical practice guidelines for peroral endoscopic myotomy. Dig Endosc. 2018 Sep;30(5):563-79.

19 Khashab MA, Sethi A, Rosch T, Repici A How to Perform a High-Quality PerOral Endoscopic Myotomy? Gastroenterology. 2019 Nov;157(5):1184-9.

20 Modayil R, Stavropoulos SN. How Many Peroral Endoscopic Myotomy Procedures Are Necessary for Proficiency? Clin Gastroenterol Hepatol. 2018 Sep;16(9):1393-7.

21 Shiwaku H, Inoue H, Yamashita K, Ohmiya T, Beppu R, Nakashima R, et al. Peroral endoscopic myotomy for esophageal achalasia: outcomes of the first over 100 patients with short-term follow-up. Surg Endosc. 2016 Nov;30(11):4817-26.

22 Zhou PH, Li QL, Yao LQ, Xu MD, Chen WF, Cai MY, et al. Peroral endoscopic remyotomy for failed Heller myotomy: a prospective single-center study. Endoscopy. 2013;45(3):1616.

23 Onimaru $\mathrm{M}$, Inoue $\mathrm{H}$, Ikeda $\mathrm{H}$, Yoshida $\mathrm{A}$, Santi EG, Sato H, et al. Peroral endoscopic myotomy is a viable option for failed surgical esophagocardiomyotomy instead of redo surgical Heller myotomy: a single center prospective study. J Am Coll Surg. 2013 Oct; 217(4):598-605. 